\title{
CONTROLE DE CONSTITUCIONALIDADE E COMPETÉNCIA DO TRIBUNAL SUPERIOR DO TRABALHO - TST (ARTIGO 702, ALÍNEA F, DA CLT)
}

Judicial Review and Competence of Superior Court of Labor - TST (Article 702 (f) in the CLT)

\section{Cristiane Catarina Fagundes de Oliveira}

Pós doutora pela UFRGS. Doutora em direito do Estado pela USP. Mestre em Direito do Estado pela UFRGS. Procuradora Municipal de Porto Alegre desde 1996 (RS, Brasil). Professora universitária.

\section{Resumo}

Este artigo está focado na ideia do controle de constitucionalidade do Supremo Tribunal Federal (STF) em relação à Reforma Trabalhista (Lei 13.467/17), especificamente a alteração da alínea f do artigo 702 da CLT. O caso é analisado, bem como as bases do controle de constitucionalidade e também as possibilidades de declaração de constitucionalidade. A conclusão é a de que poderá ser considerada inconstitucional a alteração da lei para fins de dar andamento na prestação jurisdicional trabalhista, de forma a fortalecer a centralidade institucional do Supremo Tribunal Federal. O método de análise é baseado na revisão bibliográfica e estudo de caso.

Palavras chave: Controle de Constitucionalidade. Constituição de 1988. Reforma Trabalhista. Lei Federal 13.467/17

\section{Abstract}

This paper is focused on the idea of judicial review and Brazilian Supreme Court responsibility to decide de constitutionality of New Employment Act on article 702 (f). The case is analyzed, as well as the bases of judicial review and also the possibilities of declaration of constitutionality. The conclusion is that the amendment of the law may be found unconstitutional in order to strengthen the institutional centrality of Brazilian Supreme Court. The method of analysis is based on the literature review and case study.

Keywords: Judicial review. Brazilian Constitution. New Employment Act. Federal Law 13.467/2017.

\section{Sumário}

1. Introdução; 2. Noção de controle de constitucionalidade na Constituição de $1988 ; 3$. O caso da alteração do artigo 702 , f, da CLT pela Lei 13.467/17; 4. AADC 62-DF e suas perspectivas; 5. Conclusão; Referências. 


\section{INTRODUÇÃO}

Na Reforma Trabalhista - Lei 13.467/17, especificamente a alteração da alínea fo artigo 702 da CLT criou uma situação mais rígida e nova competência para estabelecer ou alterar súmulas e outros enunciados de jurisprudência uniforme. Para isso é necessário, nos termos do novo dispositivo, o voto de pelo menos dois terços dos membros do Tribunal Pleno, caso a mesma matéria já tenha sido decidida de forma idêntica por unanimidade em, no mínimo, dois terços das turmas em pelo menos dez sessões diferentes em cada uma delas. Da mesma forma, é preciso de dois terços dos membros do Tribunal Pleno para restringir os efeitos da declaração ou decidir que ela só tenha eficácia a partir de sua publicação no Diário Oficial. Também foram incluídos os parágrafos $3^{\circ}$ e $4^{\circ}$ no mesmo artigo 702 , mas por serem complementares ao dispositivo, será feita referência em geral apenas à alínea $\mathrm{f}$, do que a discussão vale inclusive aos parágrafos.

Tendo em vista que pende arguição de inconstitucionalidade do dispositivo, suspenso o julgamento no TST, e considerando que foi também interposta ação declaratória de constitucionalidade no Supremo Tribunal Federal - STF, o estabelecimento e alteração das súmulas e de outros enunciados de jurisprudência uniforme no âmbito trabalhista estão aguardando julgamento em controle de constitucionalidade. Até uma decisão final, aguarda-se e não são alteradas inclusive sumulas contrárias à própria Reforma Trabalhista. Uma situação preocupante.

A análise inicia com a noção de controle de constitucionalidade na Constituição de 1988. Após, será examinado o caso da alteração do artigo 702, f, da CLT pela Lei 13.467/17 e, por fim, será considerada a ação declaratória de constitucionalidade - ADC 62-DF e suas perspectivas.

A ideia é observar as possiblidades de conclusão sobre a constitucionalidade do dispositivo. Será para isso importante considerar os argumentos e compreender o STF com sua centralidade institucional no sistema de controle de constitucionalidade brasileiro.

\section{NOÇÃO DE CONTROLE DE CONSTITUCIONALIDADE NA CONSTITUIÇÃO DE 1988}

Inicialmente deve-se compreender que o controle da constitucionalidade está inserido no tema da jurisdição constitucional, com enfoque em suas características essenciais presentes nos sistemas de constituição rígida, em especial na Alemanha e no Brasil. Nesse sentido, a jurisdição constitucional pressupõe um órgão ou Tribunal especial que controla, mais que as leis, a própria atividade estatal, na ideia de Estado Democrático de Direito. Desde logo, apresenta-se a questão quanto ao Brasil: há um tribunal de revisão também constitucional - o Supremo Tribunal Federal, ou este seria um Tribunal Constitucional no sentido de conceito de jurisdição constitucional (SOUZA JR, 2015).

O controle da constitucionalidade pressupõe hierarquia entre as normas existentes no sistema jurídico, em que o fundamento de validade de uma norma está naquela hierarquicamente superior que lhe determinou a criação. Nesse sentido é o princípio da supremacia da constituição, entendida esta como norma que fundamenta todo o sistema de normas no 
sentido de Kelsen (1998, p. 246-9). Dessa forma, pode-se dizer que o controle de constitucionalidade só tem lugar em sistema constitucional com constituição rígida, isto é, que possui forma peculiar e de mais difícil alteração que as do procedimento legislativo ordinário.

A maior relevância do instituto do controle da constitucionalidade reside no desenvolvimento dos princípios constitucionais (HECK, 1995) e defesa dos direitos fundamentais que asseguram o Estado Democrático de Direito. Isto porque à enumeração dos direitos fundamentais e dos princípios constitucionais postos em uma constituição, devem corresponder mecanismos jurisdicionais assegurados na própria constituição para preservá-los, resguardando-se assim a existência mesma da constituição.

Trata-se do controle de constitucionalidade no sentido jurisdicional, em que pese o tema ensejar relações com os controles político e social. Tais formas de controle são essenciais também ao controle da constituição, mas, entretanto, não são formas tão regulares e seguras, em termos de normatividade, quanto o controle jurisdicional, e daí a relevância do estudo dessa forma de controle nos termos de Aragon (1995, p. 141).

O controle de constitucionalidade aqui tratado não é o controle preventivo (CAPPELLETTI, 1992), mas o controle jurisdicional das leis em sua conformidade com a constituição. Veja-se que o sentido de lei empregado é o de ato normativo em sentido material, que compreende aqueles previstos no artigo 59 da Constituição de 1988 e ainda qualquer ato normativo oriundo do poder executivo ou judiciário e ainda que abrange inclusive as emendas constitucionais.

Com a finalidade de descrever o controle repressivo de constitucionalidade das leis, deve-se iniciar com uma noção dos sistemas de controle de constitucionalidade segundo o direito comparado - controle difuso e concentrado - e, a seguir, o sistema misto, decorrência da aplicação simultânea de mecanismos dos dois primeiros sistemas, em especial como ocorre no Brasil. De toda forma, como tendência do controle da constitucionalidade no Brasil, vê-se a progressiva importância do controle concentrado.

O sistema de controle difuso, ou também chamado concreto, tem sua origem no modelo chamado do judicial review do direito norte-americano. Pode-se dizer que, nesse caso, o controle é feito por via de exceção ou de forma incidental, isto é, sempre no curso do processo instaurado, por provocação de uma das partes, e na medida em que a decisão seja relevante para o caso concreto. Ainda que se possa vislumbrar remota origem no direito alemão, o sistema difuso, tal como é utilizado hoje, teve seu início na interpretação do art. VI da cláusula $2^{\mathrm{a}}$ da Constituição Norte-Americana pelo juiz da Suprema Corte Jorge Marshall na causa Marbury versus Madison de 1803, em que não foi concedida o ordem no writ of mandamus impetrado por Marbury, apesar de a decisão no mérito declarar seu direito, em face da preliminar de que a lei fundamento do mandamus que dava poderes à Suprema Corte para ordenar a providência impetrada era contrária à Constituição Americana (POLETTI, 1998 , p. 32). Nesse caso, foi afirmado o princípio da supremacia da Constituição e o dever de os juízes negarem a aplicação de normas contrárias à constituição. Para tal conclusão, - Chief Justice Marshall confrontou duas idéias: ou a constituição é superior e não suscetível de alteração por lei, e, se esta Ihe for contrária, não será lei, ou a Constituição escrita 
frustra-se na tentativa de limitar um poder ilimitável, não havendo meio-termo entre essas alternativas (POLETTI, 1998).

O efeito da decisão em matéria de controle difuso da constitucionalidade é declarativo ex tunc - retroativo (DINIZ, 1998). Todavia, pelo que se vê da evolução deste modo de controle, cada vez mais os juízes têm decidido pela irretroatividade da decisão de inconstitucionalidade.

A crítica mais comum a esse sistema de controle difuso se refere à sua utilização em países em que não haja a tradição de stare decisis, pois haveria uma diversidade muito grande de decisões que teriam como consequência a insegurança jurídica. É por essa razão que Miranda (1998, p. 384) apanha as críticas a esse sistema de controle baseadas no fato de que favorece a possibilidade de desarmonia dos julgados, com o conseqüente risco de desvalorização dos julgamentos de inconstitucionalidade e da própria constituição, além da possibilidade de não-acatamento das decisões pela diluição do poder de controle pelos vários órgãos existentes.

De outro lado, o controle concentrado, também chamado abstrato, cuja característica essencial é a existência de um órgão jurisdicional específico (Tribunal ordinário com essa atribuição ou Tribunal Constitucional) em que são interpostas ações próprias que versam sobre a constitucionalidade ou não de determinada lei, de forma desvinculada de um caso concreto. Por essa razão é chamado de controle por via de ação. O sistema de controle concentrado é conhecido como austríaco, eis que foi posto em prática pela Constituição Austríaca de $1^{\circ}$ de outubro de 1920, sob clara inspiração do mestre da Escola de Viena, Hans Kelsen (HECK, 1995 p. 27).

O órgão ou Tribunal Constitucional responsável pelo exame da constitucionalidade no sistema concentrado pronuncia, como regra, decisões constitutivas ex nunc (ao futuro), proibindo-se a retroatividade, exceto, na ideia de Kelsen, em relação ao controle com origem na reforma austríaca de 1929. A escolha pela criação de um órgão específico para o controle da constitucionalidade, com decisões de eficácia erga omnes surgiu para assegurar a manutenção da unidade do ordenamento jurídico. Destarte, tal órgão especial tem, no sistema concentrado, monopólio do exame - decide se é constitucional ou inconstitucional - e da rejeição da inconstitucionalidade.

Ademais, a criação de um órgão especializado em questões constitucionais, teria a função de interpretar as normas constitucionais, em uma continuidade da jurisdição ordinária - como em um corolário da carreira jurídica para os membros de tal tribunal. Mas também poderia ser a esse novo tribunal dada a importante função renovadora de estabelecimento de diretrizes dinâmicas na atividade constitucional. A lei austríaca de 1929, de revisão constitucional, modificou parcialmente esse sistema de controle, sendo possibilitado a dois tribunais a apresentação de questões de constitucionalidade a serem examinadas pelo tribunal constitucional. Após breve período de interrupção (1933 a 1946) esse sistema de controle vige ainda hoje na Áustria.

No Brasil, vige o sistema misto de controle de constitucionalidade, que é aquele que utiliza elementos do sistema difuso e do sistema concentrado simultaneamente. Pode ocor- 
rer como nos sistemas em que, apesar de se seguir os sistema difuso, são criados tribunais supremos com competências e composição semelhantes aos dos tribunais constitucionais europeus como na Espanha, Portugal e Polônia (MIRANDA, 1998).

A fim de compreender a distinção entre Tribunal Constitucional e Tribunal de Revisão, com matéria constitucional importa compreender o recurso constitucional na Alemanha (HESSE:1998). Há, de fato, uma relação entre o Tribunal Constitucional Federal Alemão e as jurisdições ordinárias, o que, todavia, não caracteriza o Tribunal como tribunal de revisão eis que o caso só é examinado em seu sentido constitucional e a decisão final ficará a cargo do tribunal de origem (MENDES, 1996, p.303).

Bonavides (2019) reconhece a ampliação do controle concentrado e faz crítica no sentido de que os particulares não podem utilizar o controle diretamente, ficando prejudicado o controle dos direitos individuais. Todavia, entende-se que a efetividade para os particulares não depende de o controle ser difuso ou concentrado, mas de ser aberta a possibilidade de um mecanismo próprio para violações sofridas diretamente pelo cidadão, no que diz respeito aos seus direitos fundamentais, como recurso constitucional existente na Alemanha.

No Brasil, ainda que se busque analogia do Supremo Tribunal Federal com os Tribunais Constitucionais Europeus, não parece haver jurisdição constitucional, se considerarmos os requisitos para se caracterizar um órgão especial de controle de constitucionalidade. São eles: 1. A sua constituição se dê por meio da sua própria constituição; 2 . Suas competências estejam estabelecidas na Constituição e 3. Compartilhe, de forma decisiva, na formação política global do Estado (HECK, 1994).

Disso percebe-se que uma ação declaratória de constitucionalidade, assim como as demais ações oriundas do controle concentrado, que integram o sistema misto no Brasil, é relevante para a consolidação do Supremo Tribunal Federal como órgão de controle de constitucionalidade por excelência. Ainda assim, não será Tribunal Constitucional de acordo com as distinções apontadas.

\title{
3. O CASO DA ALTERAÇÃO DO ARTIGO 702, I, F, DA CLT PELA LEI $13.467 / 17$
}

A Reforma Trabalhista, Lei 13.467/17, incluiu na CLT a seguinte redação à alínea f do inciso I do art. 702:

\begin{abstract}
f) estabelecer ou alterar súmulas e outros enunciados de jurisprudência uniforme, pelo voto de pelo menos dois terços de seus membros, caso a mesma matéria já tenha sido decidida de forma idêntica por unanimidade em, no mínimo, dois terços das turmas em pelo menos dez sessões diferentes em cada uma delas, podendo, ainda, por maioria de dois terços de seus membros, restringir os efeitos daquela declaração ou decidir que ela só tenha eficácia a partir de sua publicação no Diário Oficial.
\end{abstract}

É de se advertir que, da mesma forma, a Reforma Trabalhista incluiu os parágrafos $3^{\circ}$ e $4^{\circ}$ no mesmo dispositivo do art. 702 :

§3o As sessões de julgamento sobre estabelecimento ou alteração de súmulas e outros enunciados de jurisprudência deverão ser públicas, divulgadas com, no mínimo, trinta dias de antecedência, e deverão possibilitar a sustentação oral pelo Procurador-Geral do Trabalho, pelo Conselho Federal da Ordem dos Advogados do Brasil, pelo Advogado-Geral da União e por confederações sindicais 


\begin{abstract}
ou entidades de classe de âmbito nacional.
$\S 40$ O estabelecimento ou a alteração de súmulas e outros enunciados de jurisprudência pelos Tribunais Regionais do Trabalho deverão observar o disposto na alínea $f$ do inciso I e no §3o deste artigo, com rol equivalente de legitimados para sustentação oral, observada a abrangência de sua circunscrição judiciária.
\end{abstract}

De início a questão fica centrada no fato de que o artigo 702 estava revogado tacitamente ou expressamente como sustenta Lisboa e Munhoz (2018, p. 347) diante da Lei 7.701 de 1988. Tal lei disciplinou a competência do tribunal pleno e expressamente revogou o que fosse incompatível com a CLT. Assim, não é possível existir uma alínea "f" onde não há artigo nem inciso em vigor, sob pena de afrontar a Lei Complementar 95/1998, art. 18 e a LINDB, art. $2^{\circ}, \S^{\circ}$.

Para resolver tal problema, o TST, editou Resolução Administrativa n¹937/17 adaptando seu regimento interno à Reforma Trabalhista, Lei 13.467/17, incluindo a disposição da dita alínea "f". Tal soluciona, parece, a questão da ilegalidade, mas há movimentos evidenciados na sessão plenária TST de 06.02.2018 (LISBOA; MUNHOZ, 2018, p. 351) no sentido da possibilidade de nova alteração no Regimento Interno.

Sendo assim, o TST estava a preparar o debate, em sessão do pleno, para as alterações sumulares que a comissão própria a esse fim havia analisado, quando foi interposta Ação Declaratória de Constitucionalidade - ADC62/DF, com pedido liminar, ajuizada pela Confederação Nacional do Sistema Financeiro - CONSIF, pela Confederação Nacional do Turismo - CNTUR e pela Confederação Nacional do Transporte - CNT tendo por objeto o art. 702, I, f e outros da Consolidação das Leis Trabalhistas - CLT, com a redação dada pela Lei $13.467 / 2017$.

Com a interposição da ADC, o Tribunal Superior do Trabalho decidiu em sessão extraordinária do Tribunal Pleno, suspender o julgamento de arguição de inconstitucionalidade de parte do artigo 702 da Consolidação das Leis do Trabalho - CLT (Arglnc-696-25.2012.5.05.0463) e da proposta elaborada pela Comissão de Jurisprudência e de Precedentes Normativos para adequar algumas súmulas e orientações jurisprudenciais do TST a alterações da CLT. Essa decisão do TST foi amplamente divulgada (TST, 2019) e não foi concedida liminar na ADC pelo Ministro relator no STF.

À época, o ministro Brito Pereira, presidente do TST assim se manifestou (TST, 2019): "A suspensão não revela abandono de nossa competência jurisdicional para exercer o controle difuso, mas apenas cautela diante da existência da ADC em curso e em deferência ao Supremo Tribunal Federal". Ainda se aguarda, até o fechamento desse artigo, um deslinde para a ADC.

Atualmente há um preocupante paradoxo junto ao Tribunal Superior do Trabalho. De um lado, visando a segurança jurídica, é preciso adequar as suas súmulas e orientações jurisprudenciais à Lei 13.467/2017, mas, de outro lado, a discussão da eventual inconstitucionalidade da lei própria lei impede o prosseguimento. Todavia, a indefinição jurisprudencial não impediu que o tribunal aumentasse a sua produtividade em 2018. Julgou quase 320 mil casos, aumento de $12 \%$ em relação a 2017, quando foram julgados 285 mil processos. Do total de julgados em 2018, 63\% consistiram em Agravos de Instrumento em Recurso 
de Revista, somando 202 mil. Em seguida foram apreciados os Recursos de Revista, que totalizaram 45 mil casos (HYLDA, 2019).

\title{
4. A ADC 62-DF E SUAS PERSPECTIVAS
}

\section{A ação declaratória de constitucionalidade - ADC 62-DF foi interposta em 18 de março} de 2019, com decisão inicial no seguinte sentido:

\begin{abstract}
Trata-se de Ação Declaratória de Constitucionalidade - ADC com pedido liminar ajuizada pela Confederação Nacional do Sistema Financeiro - CONSIF, pela Confederação Nacional do Turismo - CNTUR e pela Confederação Nacional do Transporte - CNT tendo por objeto o art. 702, I, f e $\S 3^{\circ}$ e $\S 4^{\circ}$, da Consolidação das Leis Trabalhistas - CLT, com a redação dada pela Lei 13.467/2017. Os requerentes apontam a existência de controvérsia judicial relevante sobre a constitucionalidade da norma constante do art. 702, I, f, da CLT, apta a autorizar o ajuizamento da $A D C$. Prosseguem asseverando que, da regra extraída do referido art. 702

"[...] resulta um nível de segurança muito maior para todos os que, de algum modo, se sujeitarão aos efeitos da criação, revisão ou cancelamento de uma súmula ou enunciado de jurisprudência na Justiça do Trabalho" (pág. 23 da inicial), de modo que a rigidez dos novos requisitos tornam o processo "[...] seguro para permitir a consolidação de um entendimento jurisprudencial maduro que, por sua vez, também trará segurança, previsibilidade para a prestação jurisdicional, concepção essa análoga à de que o processo precisa ser justo em si mesmo para conduzir a um resultado justo" (pág. 26 da inicial).
\end{abstract}

Destacam, ainda, que "os requisitos trazidos na redação nova do art. 702 são proporcionais e razoáveis, porque necessários e potencialmente mais adequados à finalidade pretendida do que aqueles anteriormente previstos no Regimento Interno do TST" (pág. 31 da inicial), de maneira que os "[...] vícios de inconstitucionalidade material que Ihe foram imputados no incidente de arguição de inconstitucionalidade processado na origem, a regra nova do art. 702 , inciso I, alínea ' $f$ ', parágrafos $3^{\circ}$ e $4^{\circ}$, da CLT faz cessar a ofensa a normas constitucionais que já foram, por vezes, inobservadas pelo TST [...]" (pág. 32 da inicial). Para justificar o pedido de concessão da medida cautelar, destacam a "[...] iminência de julgamento de incidente de arguição de inconstitucionalidade, pelo TST, de que poderá resultar o completo esvaziamento de regra absolutamente legítima, considerando que a decisão proferida em tal incidente inspirará a criação de súmula e vinculará outras decisões a respeito do tema no TST.

[...] Já se viu que, à semelhança do que ocorreu nas semanas de 2011 (entre os dias 16 e 20 de maio) e 2012 (entre os dias 10 a 14 de setembro), em que houve a aprovação e alteração de várias súmulas e orientações jurisprudenciais, o TST pautou também para a sessão do próximo dia 20 de março - a mesma em que, em princípio, será julgada a arguição de inconstitucionalidade do art. 702, I, F, e $\S \S 3^{\circ}$ e $4^{\circ}$ da $C L T$ - a apreciação das propostas da Comissão de Jurisprudência e de Precedentes Normativos de revisão de vários verbetes da jurisprudência consolidada do TST. Há o risco iminente de serem revistas 14 súmulas e 5 orientações jurisprudenciais, sem que sejam observados os requisitos previstos no dispositivo de lei cuja constitucionalidade se pretende seja declarada nesta ação, o que norteará o julgamento de inúmeras ações em curso e que virão a surgir" (pág. 32-33 da inicial).

Os principais argumentos para a constitucionalidade da alteração do art. 702, f, como se vê, está na estabilidade das súmulas e outros enunciados de jurisprudência do TST. Com a declaração de constitucionalidade, o Tribunal precisaria de dois terços de seus membros para realizar alterações, como já havia preparado por meio de comissão, exatamente após analisar o impacto das demais alterações da Reforma Trabalhista.

De fato, como analisa Guimarães (2018, p. 1184-1185) "andou bem o legislador ao inserir os criteriosos dispositivos em destaque." Isso porque é importante preservar a segurança. E o princípio da segurança jurídica, em especial em matéria sumular, é um dos pilares 
do ordenamento jurídico brasileiro.

Ademais, pode-se entender que o próprio TSE, ao início, quando incorporou o texto da alínea "f" ( e parágrafos) ao seu regimento interno, aceitou a Reforma nesse ponto como constitucional. Conforme entendimento de Melek (2017, p.219), o dispositivo "visa democratizar a jurisprudência e dar mais estabilidade às decisões."

De outro lado, pela inconstitucionalidade da alteração legislativa, pode-se referir que há contrariedade aos artigos $2^{\circ} ; 5^{\circ}$, caput e LXXVIII; 93, X e XI; 96, I, a; 99, caput e 103A da Constituição de 1988.

Inicialmente, o Poder Legislativo não pode intervir de tal modo na autonomia do Poder Judiciário por lei ordinária, sem quórum qualificado, interferindo em funcionamento de Tribunal. O próprio Supremo Tribunal Federal poderia ser alvo de legislação ordinária. A garantia a ser preservada é da independência dos poderes de Estado garantida no artigo $2^{\circ}$ da Constituição de 1988.

De outra parte, a duração razoável do processo, prevista no art. $5^{\circ}$, LXXVIII restará sobremaneira prejudicada. É que a imposição de "dois terços dos membros", bem como "dois terços das turmas em pelo menos dez sessões diferentes em cada uma delas" cria dificuldade irrazoável. Uma vez que haja dificuldades no estabelecimento e alteração das súmulas e enunciados, relacionando-se com a nova sistemática do Código de Processo Civil para função sumular, o número de recursos judiciais tende a aumentar com prejuízo da celeridade.

Tal alteração, dirigida apenas à Justiça do Trabalho também se mostra desigual, aplicando-se por analogia o princípio da igualdade do art. $5^{\circ}$, caput. Assim, compreende-se o tratamento desigual entre os diferentes ramos do Poder Judiciário, o que contraria a Constituição de 1988. Veja-se que foi a própria Constituição de 1988, no art. 103A que definiu o quórum de dois termos ao STF e nada mencionou aos tribunais da Justiça do Trabalho.

Ademais, a ofensa constitucional se refere especificamente à intromissão legislativa nos órgãos internos dos tribunais do trabalho, com determinação de procedimentos para a estabilização da jurisprudência uniforme ou sumulada (Lisboa; Munhoz, 2018, p.345). Nesse sentido o dispositivo determina competência ao órgão pleno que não mais havia regimentalmente, ferindo a autonomia administrativa do Poder Judiciário para elaborar seu regimento, consagrada constitucionalmente nos artigos 96, I, a e 99, caput. Veja-se que a autonomia do Poder Judiciário nas questões administrativas está consagrada no art. 93, X e XI.

Portanto, há que se aguardar a posição do Supremo Tribunal Federal sobre a constitucionalidade ou não da lei em comento.

\section{CONCLUSÃO}

A conclusão é no sentido de que importa ao Supremo Tribunal Federal, em vista do sistema de controle concentrado misto no Brasil, com órgão de revisão e não Tribunal Constitucional em jurisdição constitucional, que seja protagonista na solução do impasse preocupante causado na justiça do trablaho. 
Portanto, em vista dos argumentos trazidos, poderá ser considerada inconstitucional a alteração da lei, de forma a fortalecer a centralidade institucional do Supremo Tribunal Federal. De qualquer sorte, urge resolver o impasse para fins de dar andamento na prestação jurisdicional trabalhista.

\section{REFERÊNCIAS}

ARAGON, Manuel. Constituicion y Control del Poder. Buenos Aires: Ediciones Ciudad Argentina, 1995.

BONAVIDES, Paulo. Curso de Direito Constitucional. 34. ed. São Paulo: Malheiros, 2019.

BRASIL. Constituição da República Federativa do Brasil. Disponível em: http://www.planalto.gov.br/ ccivil_03/constituicao/constituicao.htm. Acesso em: 01 ago. 2019.

CAPPELLETTI, Mauro. O Controle Judicial de Constitucionalidade das Leis no Direito Comparado. Porto Alegre: Sérgio Fabris, 1992.

CAVALCANTI, Hylda. TST depende do Supremo para consolidar aplicação da reforma trabalhista. Conjur, São Paulo, 01 jun. 2019. Disponível em: https://www.conjur.com.br/2019-jun-01/anuario-tst-depende-stfconsolidar-aplicacao-reforma. Acesso em: 01 jun. 2019.

DINIZ, Márcio Augusto Vasconcelos. Constituição e Hermenêutica Constitucional. Belo Horizonte: Mandamentos, 1998.

GUIMARÃES, Ricardo Pereira de Freitas. CLT Comentada. 2. ed. rev., atual. e ampl. São Paulo: RT, 2018.

HECK, Luis Afonso. O Recurso Constitucional na sistemática jurisdiconal-constitucional alemã. Revista de Informação Legislativa, Brasília, p. 115-133, out./dez. 1994.

HECK, Luís Afonso. O Tribunal Constitucional Federal e o Desenvolvimento dos Princípios Constitucionais. Porto Alegre: Sérgio Fabris, 1995.

HESSE, Konrad. Elementos de Direito Constitucional da República Federal da Alemanha. Tradução de Luís Afonso Heck. Porto Alegre: Sérgio Fabris, 1998.

HORTA, Raul Machado. Direito Constitucional. 4. ed. Belo Horizonte: Del Rey, 2003.

KELSEN, Hans. Teoria Pura do Direito. Tradução de João Baptista Machado. São Paulo: Martins Fontes, 1998.

LISBOA, Daniel; MUNHOZ, José Lúcio (org.). Reforma Trabalhista. São Paulo: LTr, 2018.

MELEK, Marlos Augusto. Trabalhista! O que mudou? Curitiba: Estudo Imediato, 2017.

MENDES, Gilmar Ferreira. Jurisdição Constitucional. 5. ed. São Paulo: Saraiva, 2014.

MIRANDA, Jorge. Manual de Direito Constitucional. Coimbra: Coimbra Editora, Tomos I e II, 1988. 
POLETTI, Ronaldo. Controle da Constitucionalidade das Leis. Rio de Janeiro: Forense, 1998.

SILVA, José Afonso da. Teoria do Conhecimento Constitucional. São Paulo: Malheiros, 2014.

SOUZA JUNIOR, Cezar Saldanha. O Tribunal Constitucional como poder. 2. ed. São Paulo: RT, 2015.

TST. TST suspende exame de inconstitucionalidade do artigo 702 da CLT. Tribunal Superior do Trabalho, Brasília, 2019. Notícias. Disponível em: http://www.tst.jus.br/noticias/-/asset_publisher/89Dk/ content/tst-suspende-exame-de-inconstitucionalidade-do-artigo-702-da-clt. Acesso em: 20 mar. 2019.

Recebido em: 30/12/2020

Aceito em: 30/12/2020 